\title{
COP enhancement and comparison of different absorption cooling systems
}

\author{
Nihel Ben Zid ${ }^{1 *}$, Nejib Hajji ${ }^{1}$, Mohamed.El Ganaoui ${ }^{2}$ \\ 1. National Engineering School of Gabes, University of Gabes, 6072 Gabes, Tunisia. \\ 2. Universityvof Lorraine, (France)
}

\begin{abstract}
The absorption refrigeration machines represent a good alternative to compression refrigeration machines but the major problem of this type of refrigeration lies in the COP, which seems to be less efficient. Several researches are carried out to improve the performances of these machines such as the combination with the technology of the ejectors. In this work, we are interested in the three ammonia-water absorption cycles: Single effect absorption, Ejector-absorption and Combined ejector-flash tank absorption cycles. A gas-gas ejector would be installed between the generator and the condenser. We suppose that adding a flash tank between the condenser and the evaporator could help improve the entrainment ratio of the ejector. We used simulations in order to compare the performances of these three different cycles. The simulation results demonstrate that the combined ejector-flash tank absorption cycle performs better than others.
\end{abstract}

\section{Introduction}

Use Mechanical vapor compression refrigeration is widely known for its negative effect on the environment. Finding new alternatives may help achieve energy efficient systems with low environmental impact. In this context, the absorption technology for refrigeration is generating great interest due to the fact that the source of energy used in the generator is renewable. This technology uses as working fluids solutions that incorporate natural refrigerants; the most common are $\mathrm{H} 2 \mathrm{O}-\mathrm{LiBr}$ and $\mathrm{NH} 3-\mathrm{H} 2 \mathrm{O}$. Therefore, several researches are carried out to improve the performances of these machines through combining them, for example, with the technology of the ejectors. Sun [1] studied this cycle working with the $\mathrm{LiBr}-\mathrm{H} 2 \mathrm{O}$ couple, he compared it to that of the single-effect cycle and he noticed a considerable improvement of the COP. Chen [2] examined a combined cycle with R22 / DME-TEG and he showed that there is an improvement in COP compared to the conventional cycle, especially at lower generator temperatures. R.Sirwan [3] studied a modification of the absorption ejector cycle. This modification consists of adding a vapor-liquid separator and a booster. A computer simulation using Fortran 90 program was developed to analyze the performance of the modified combined cycle. He concluded that an improvement in the performance of this cycle can be reached using this method. In this work, we are interested in the three ammonia-water absorption cycles and we used simulations by Aspen-Hysys in order to compare the performances of these three different cycles.

\section{Analysis and modelling}

\footnotetext{
$\bar{*}$ Corresponding author: benzidnihel@gmail.com
}

\subsection{Single effect absorption cycle}

The description of the operating principle of the absorption machine is provided (Figure 1) [4]:

The vapor of the refrigerant produced in the evaporator is absorbed in the absorber by the refrigerant-poor solution, this absorption is carried out with a temperature increase while pressure stays almost the same (Absorber pressure $=$ Evaporator pressure). The rich solution goes from low pressure (BP) to high pressure (HP) through the pump. It is preheated in the exchanger by the poor solution coming from the generator. Then it enters the generator in 1 where it is heated to the boiling temperature of the refrigerant, then the vapor of the refrigerant produced (1) goes to the condenser where it is condensed. An expansion takes place in the expansion valve from HP to BP. This is accompanied by a cooling of the liquid refrigerant and a partial vaporization. The remainder of the liquid refrigerant is evaporated in the evaporator usually at constant temperature by absorbing a heat from the cold source. Returning to the cycle of thermal compression, the poor solution produced in the generator is cooled in the exchanger (7-8) then it is expanded (8-9) before going to the absorber and the cycle is repeated. $[5,6]$

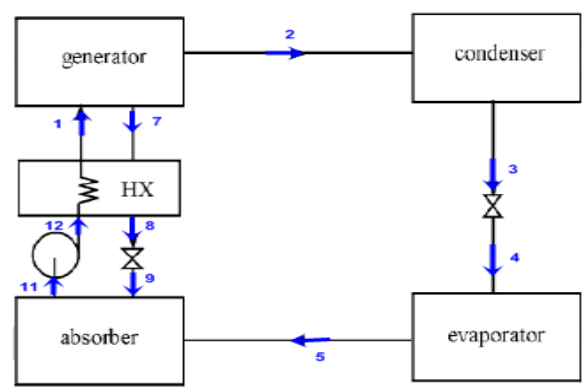

Figure 1: Schematic representation of absorption cycle. 
The absorption cycle analysis is based on the following assumptions:

- Pressure drops and heat losses are neglected.

- Expansion is supposed to be isenthalpic.

The COP of the cycle can be calculated by the following equation

$$
C O P=\frac{Q_{e}}{Q_{g}+W_{p}}
$$

With Qe: the heat exchanged in the evaporator

Qg: the heat exchanged in the generator Wp: the pump work

\subsection{Ejector-absorption cycle}

The ejector is a static device based on the effect of Venturi that uses the kinetic energy of a drive fluid, injected under pressure by a convergent or convergentdivergent nozzle into a lower pressure zone, to suck and drive a secondary fluid at low pressure and to compress the mixed flow thus obtained at the desired intermediate pressure.

In this configuration (figure 2), the gas-gas ejector is placed between the generator and the condenser which will suck up a quantity of vapor of the refrigerant coming from the evaporator.

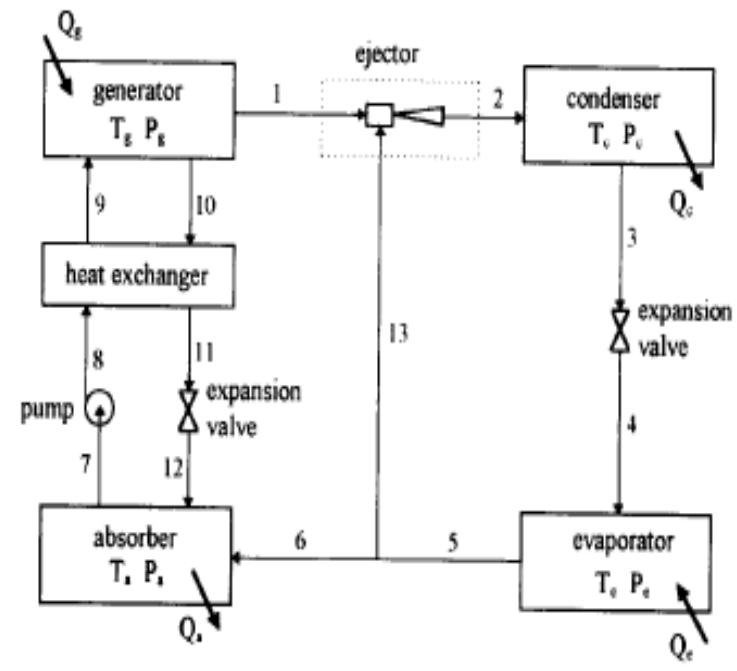

Figure 2: The combined ejector-absorption cycle

\subsection{Combined ejector-flash tank absorption cycle}

In this configuration, we suppose that adding a flash tank between the condenser and the evaporator could help improve entrainment ratio of the ejector. The combined cycle ejector-absorption is shown below.

\subsection{Ejector modelling}

To predict the performance of the ejector, we present a method to define the ejectors so as to enhance their adaptation in the absorption machine. We will focus more particularly on compressible fluid ejectors with a cylindrical mixing chamber by using the integral method for dimensioning the ejector. The method used, known as the "integral" or "thermodynamic model", is based on the model of the one-dimensional isentropic flow of ideal gases. [7]

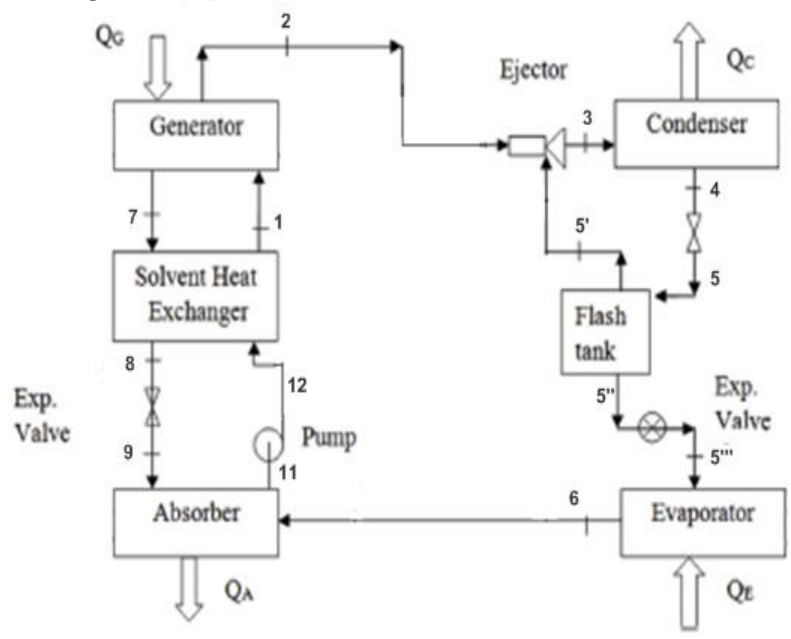

Figure 3: The combined Flash ejector-absorption cycle

This model is based on the fundamental principles of conservation of mass, momentum and energy.

Continuity Equation:

$\mathrm{q}_{3}=\mathrm{q}_{1}+\mathrm{q}_{2}$

Momentum Equation:

$\mathrm{P}_{1} \mathrm{~S}_{1}+\mathrm{q}_{1} \mathrm{~V}_{1}+\mathrm{P}_{2} \mathrm{~S}_{2}+\mathrm{q}_{2} \mathrm{~V}_{2}=\mathrm{P}_{3} \mathrm{~S}_{3}+\mathrm{q}_{3} \mathrm{~V}_{3}$

Energy Equation:

$\mathrm{q}_{1} \mathrm{~h}_{1}+\mathrm{q}_{2} \mathrm{~h}_{2}=\mathrm{q}_{3} \mathrm{~h}_{3}$

We exploited this model, from the reference YM. Antonio et al, for the calculation of the pressure at the exit of the ejector and the characteristic dimensions of the ejector.

At the mixing chamber inlet, the static pressures P1 and P2 are equal.

According to the following equations (5) and (6) which were deduced from the envelope curve, we can calculate the pressure at the exit of the ejector, the use of the envelope curve provides a very good idea of the device to be dimensioned so we can calculate the entrainment ratio q2/q1 or vice versa.

In this study, we have imposed the entrainment ratio q2/q1 (obtained by Aspen Hysys simulation), therefore we can determine the outlet pressure $\operatorname{Pr} 3$.

This envelope curves depend on many parameters: the total pressures $\mathrm{P} 1$ of the motive fluid and P2 of the induced fluid, the associated total temperatures $\mathrm{T} 1, \mathrm{~T} 2$, the entrainment ratio $\mathrm{q} 2 / \mathrm{q} 1$ (driving flow/induced flow) or the total outlet pressure $\operatorname{Pr} 3$.

$\frac{P_{r 3}^{\frac{\gamma_{3}-1}{\gamma_{3}}}-P_{2}^{\frac{\gamma_{2}-1}{\gamma_{2}}}}{P_{1}^{\frac{\gamma_{1}-1}{\gamma_{1}}}-P_{r 3}^{\frac{\gamma_{3}-1}{\gamma_{3}}}}\left(\frac{P_{1}^{\frac{\gamma_{1}-1}{\gamma_{1}}}}{P_{2}^{\frac{\gamma_{2}-1}{\gamma_{2}}}}\right)=f\left(\frac{q_{2}}{q_{1}} \sqrt{\frac{r_{2} T_{2} \gamma_{1}}{r_{1} T_{1} \gamma_{2}}}\right)$

$\mathrm{Y}=0.3855 \mathrm{x}-1.114$ 
We assume that the primary fluid and the secondary fluid have the same ratio of the thermal capacities

$$
\begin{aligned}
& \gamma=\frac{C p}{C v} . \\
& Y=f\left(\frac{q_{2}}{q_{1}} \sqrt{\frac{T_{2}}{T_{1}}}\right)=\frac{P_{r 3}^{\frac{\gamma_{3}-1}{\gamma_{3}}}-P_{2}^{\frac{\gamma_{2}-1}{\gamma_{2}}}}{P_{1}^{\frac{\gamma_{1}-1}{\gamma_{1}}}-P_{r 3}^{\frac{\gamma_{3}-1}{\gamma_{3}}}}\left(\frac{P_{1}^{\frac{\gamma_{1}-1}{\gamma_{1}}}}{P_{2}^{\frac{\gamma_{2}-1}{\gamma_{2}}}}\right)
\end{aligned}
$$

To simplify the equation (8), we suppose that:

$$
A=\left(\frac{P_{1}^{\frac{\gamma_{1}-1}{\gamma_{1}}}}{P_{2}^{\frac{\gamma_{2}-1}{\gamma_{2}}}}\right)
$$

After simplifying, we obtain the following equation:

$$
P_{r 3}=\left(\frac{P_{1}^{\frac{\gamma_{1}-1}{\gamma_{1}}} \cdot Y+P_{2}^{\frac{\gamma_{2}-1}{\gamma_{2}}} \cdot A}{A+Y}\right)^{\frac{\gamma_{3}}{\gamma_{3}-1}}
$$

\subsection{Ejector efficiency}

The total efficiency of an ejector results can be defined by the ratio between the compression energy recovered on total flow and the energy spent on the driving flow expansion in the nozzle.

The expression of the ejector efficiency is the following:

$$
\eta e j=\frac{q_{3}\left(\gamma_{1}-1\right) T_{3} \gamma_{3} r_{3}\left[1-\left(\frac{P_{2}}{P_{3}}\right)^{\frac{\gamma_{3}-1}{\gamma_{3}}}\right]}{q_{1}\left(\gamma_{3}-1\right) T_{1} \gamma_{1} r_{1}\left[1-\left(\frac{P_{2}}{P_{1}}\right)^{\frac{\gamma_{1}-1}{\gamma_{1}}}\right]}
$$

\section{Results and discussion}

The work done is based on the modeling and simulation of the refrigeration machine using the Aspen-Hysys software which is an advanced flow-sheeting tool for process simulation. It has a rich library of model calculations of thermodynamic properties.

Stated below in table 1 are the characteristics of the generator's inlet in 1.

Table 1: Characteristics of the generator's inlet

\begin{tabular}{|c|c|}
\hline Parameters & Values \\
\hline Temperature $\left({ }^{\circ} \mathrm{C}\right)$ & 67.7 \\
\hline Pressure $(\mathrm{kPa})$ & 1167 \\
\hline Mass Flowrate $(\mathrm{kg} / \mathrm{h})$ & 213 \\
\hline x NH3 $(\%)$ & 52 \\
\hline x H2O $(\%)$ & 48 \\
\hline
\end{tabular}

In this work we modeled and simulated all three types of absorption cycles. However only the combined ejectorflash tank absorption is represented with Aspen-Hysys. Figure 5 illustrates the combined ejector-flash tank absorption cycle model in Aspen-Hysys. Figure 5 illustrates the combined ejector-flash tank absorption cycle model in Aspen-Hysys.

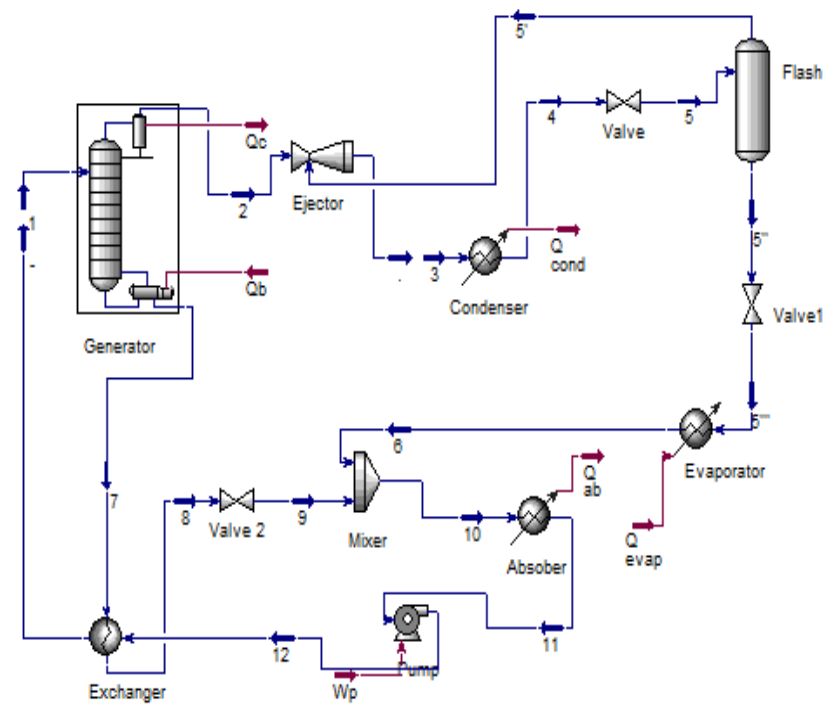

Figure 5: The Flash ejector- absorption machine model

The results of the Aspen-Hysys simulation for the main components of these three cycles are shown in Table 2. In this configuration, the ejector has compressed a portion of the low pressure steam to reinject it into the condenser $(\operatorname{Pr} 3=1128 \mathrm{kPa}($ Cycle 2$)$ and $\operatorname{Pr} 3=1130 \mathrm{kPa}$ (cycle 3 ). Hence, the refrigerant flow circulating in the condenser and the evaporator will increase $(\mathrm{m}$ cond $=$ $57.95 \mathrm{~kg} / \mathrm{h}$ to $\mathrm{m}$ cond $=63.2 \mathrm{~kg} / \mathrm{h}$ (cycle 2$)$ and $\mathrm{m}$ cond $=$ $61.53 \mathrm{~kg} / \mathrm{h}$ (cycle 3 ) and (m evap $=57.95 \mathrm{~kg} / \mathrm{h}$ to $\mathrm{m}$ evap $=63.2 \mathrm{~kg} / \mathrm{h}$ (cycle 2$)$ and m evap $=58.63 \mathrm{~kg} / \mathrm{h}($ cycle 3 ), which will increase the cooling effect thereby enhancing the COP.

We can conclude that the combined ejector flash absorption cycle provides potentially a COP of around of $76 \%$ higher than that of the single effect absorption cycle $(\mathrm{COP}=64 \%)$ and that of ejector-absorption cycle $(\mathrm{COP}=$ $73 \%)$.

\section{Conclusion}

This paper describes three refrigeration cycles: the single effect absorption cycle, the ejector-absorption cycle and the combined ejector-flash tank absorption cycle. A gasgas ejector was installed between the generator and the condenser of two cycles to improve the performance of the absorption machine. A HYSYS simulation was conducted for all these cycles and used to determine the performance of the system. A significant increase in the cooling capacity was remarked and the combined cycle provides potentially a COP of around of $76 \%$ higher than 
that of the single effect absorption cycle $(\mathrm{COP}=64 \%)$ and that of the ejector absorption cycle ( $\mathrm{COP}=73 \%)$.

\begin{tabular}{|c|c|c|c|c|}
\hline Parameters & Components & $\begin{array}{l}\text { Single } \\
\text { effect } \\
\text { cycle } \\
(1)\end{array}$ & $\begin{array}{l}\text { Ejector- } \\
\text { absorption } \\
\text { cycle (2) }\end{array}$ & $\begin{array}{c}\text { ejector- } \\
\text { flash tank } \\
\text { absorption } \\
\text { cycle (3) }\end{array}$ \\
\hline \multirow{4}{*}{$\begin{array}{c}\text { Temperature } \\
\left({ }^{\circ} \mathrm{C}\right)\end{array}$} & Generator & 103.6 & 104 & 103 \\
\hline & Condenser & 30 & 18 & 25 \\
\hline & Evaporator & 1 & 1 & 1 \\
\hline & Absorber & 24.6 & 24.75 & 24.4 \\
\hline \multirow{4}{*}{$\begin{array}{l}\text { Pressure } \\
(\mathrm{kPa})\end{array}$} & Generator & 1167 & 1167 & 1167 \\
\hline & Condenser & 1167 & 1128 & 1130 \\
\hline & Evaporator & 327 & 327 & 327 \\
\hline & Absorber & 327 & 327 & 327 \\
\hline \multirow{4}{*}{ x NH3 (\%) } & Generator & 33.38 & 33.32 & 33.4 \\
\hline & Condenser & 99.93 & 99.93 & 99.93 \\
\hline & Evaporator & 99.93 & 99.93 & 99.94 \\
\hline & Absorber & 52 & 51.8 & 52 \\
\hline \multirow{4}{*}{ X H2O (\%) } & Generator & 66.62 & 66.68 & 66.6 \\
\hline & Condenser & 0.07 & 0.07 & 0.07 \\
\hline & Evaporator & 0.07 & 0.07 & 0.06 \\
\hline & Absorber & 48 & 48.2 & 48 \\
\hline \multirow{4}{*}{$\begin{array}{c}\text { Mass } \\
\text { Flowrate } \\
(\mathrm{Kg} / \mathrm{h})\end{array}$} & Generator & 155 & 154 & 156.9 \\
\hline & Condenser & 57.98 & 63.2 & 61.53 \\
\hline & Evaporator & 57.98 & 63.2 & 58.63 \\
\hline & Absorber & 213 & 211.5 & 214.9 \\
\hline Q ev (KW) & --- & 18.19 & 20.84 & 19.73 \\
\hline Q g (KW) & --- & 28.16 & 28.36 & 25.8 \\
\hline Wp (KW) & --- & 0.08 & 0.08 & 0.09 \\
\hline $\operatorname{COP}(\%)$ & --- & 64 & 73 & 76 \\
\hline
\end{tabular}

\section{References}

1. D.W. Sun, I.W. Eames, S. Aphornratana, Int J. Refreg., 19(3), 172 (1996).

2. L.T. Chen, Appl Energy. 30:37 (1998).

3. R. Sirwan, M.A. Alghoul, K. Sopian, Y. Ali, Appl. Ther. Eng., 58(1), 85 (2013).

4. P. Srikhirin, S. Aphornratana, P.S. Chungpaibul, Renew. Sust. Energy Rev., 5(4), 343 (2001).

5. D.W. Sun, Energy Conver. Manag., 39(5), 357 (1998).

6. H. Dardour, PhD Thesis, Pau-France, (2012).

7. Y.M. Antonio, C. Périlhon, G. Descombes, C. Chacoux, Entropy, 14(4), 599 (2012). 